\title{
Contribution of industry funded post-marketing studies to drug safety: survey of notifications submitted to regulatory agencies
}

\author{
Angela Spelsberg, ${ }^{1,2}$ Christof Prugger, ${ }^{3}$ Peter Doshi, ${ }^{4}$ Kerstin Ostrowski, ${ }^{2}$ Thomas Witte, ${ }^{2}$ \\ Dieter Hüsgen, ${ }^{1}$ Ulrich Keil ${ }^{1,5}$ for the Working Group on Health and Working Group on \\ Freedom of Information, Transparency International Deutschland eV
}

${ }^{1}$ Transparency International Deutschland eV, Working Group on Health and Working Group on Freedom of Information, Alte Schönhauser Strasse 44, 10119 Berlin, Germany

${ }^{2}$ Comprehensive Cancer Centre Aachen, Pauwelsstrasse 30, 52074 Aachen, Germany

${ }^{3}$ Institute of Public Health, Charité - Universitätsmedizin Berlin, Seestrasse 73, 13347 Berlin, Germany

4University of Maryland School of Pharmacy, Pharmaceutical Health Services Research Department, Baltimore, MD USA

${ }^{5}$ Institute of Epidemiology and Social Medicine, University of Münster, Albert Schweitzer Campus, 48149 Münster, Germany

Correspondence to: A Spelsberg spelsberg@tuzac.de

Cite this as: BMJ 2017;356:j337 http://dx.doi.org/10.1136/bmj.j337

Accepted: 05 January 2017

\section{ABSTRACT}

\section{OBJECTIVES}

To investigate the practice of post-marketing studies in Germany during a three year period and to evaluate whether these trials meet the aims specified in the German Medicinal Products Act.

DESIGN

Survey of notifications submitted to German regulatory agencies before post-marketing studies were carried out, 2008-10.

SETTING

Notifications obtained through freedom of information requests to the three authorities responsible for registering post-marketing studies in Germany.

\section{MAIN OUTCOME MEASURES}

Descriptive statistics of post-marketing studies, including the products under study, intended number of patients, intended number of participating physicians, proposed remunerations, study plan and protocol, and availability of associated scientific publications and reports on adverse drug reactions.

\section{RESULTS}

Information was obtained from 558 studies, with a median of 600 (mean 2331, range 2-75000) patients and $63(270,0-7000)$ participating physicians per study. The median remuneration to physicians per patient was $€ 200$ (€441, €0-€7280) ( $£ 170, £ 0-£ 6200$; $\$ 215, \$ 0-\$ 7820)$, with a total remuneration cost of more than $€ 217 \mathrm{~m}$ for 558 studies registered over the three year period. The median remuneration per participating physician per study was $€ 2000$ (mean $€ 19424)$, ranging from $€ 0$ to $€ 2080000$. There was a broad range of drugs and non-drug products, of which only a third represented recently approved drugs. In

\section{WHAT IS ALREADY KNOWN ON THIS TOPIC}

Systematic evaluations of post-marketing industry funded trials are sparse

The few studies available have criticised post-marketing studies for their low scientific value and lack of scientific integrity and for being seeding trials masking marketing interests of the sponsors as research

Current legislation relies on post-marketing studies for drug safety surveillance

\section{WHAT THIS STUDY ADDS}

Post-marketing studies are not serving as a key tool for drug safety surveillance, at least among those registered in Germany

Sample sizes are generally too small to allow for the detection of rare adverse drug reactions, and many participating physicians are strictly obliged to maintain confidentiality towards the sponsor about all data, including adverse drug reactions The post-marketing studies analysed are doing no measurable good to patients and could be taking resources away from more effective pharmacovigilance systems many notifications, data, information, and results were, by contract, strictly confidential and the sole property of the respective sponsor. No single adverse drug reaction report could be identified from any of the 558 post-marketing studies. Less than $1 \%$ of studies could be verified as published in scientific journals.

\section{CONCLUSIONS}

Post-marketing studies are not improving drug safety surveillance. Sample sizes are generally too small to allow the detection of rare adverse drug reactions, and many participating physicians are strictly obliged to maintain confidentiality towards the sponsor. High remuneration and strict confidentiality clauses in these studies could influence the physicians' reporting behaviours of adverse drug reactions.

\section{Introduction}

Post-marketing studies are a major activity in the life cycle of a licensed drug/medicinal product and are regularly conducted by pharmaceutical companies and contract research organisations. Regulatory agencies rely on such industry funded studies for surveillance of drug safety. In particular, the detection of "rare" (1 in $1000)$ and "very rare" (1 in 10000) adverse drug reactions is often possible only with post-marketing studies. ${ }^{1}$

According to the German Medicinal Products Act (Arzneimittelgesetz, AMG) all companies initiating a post-marketing study in the German drug market are required by law to register their study. The act specifies that the purpose of such studies is to investigate the use of medicinal products in daily routine, to assess rare adverse drug reactions, and to improve long term drug safety. ${ }^{2}$ To our knowledge there is no such law in other countries requiring all post-marketing studies to be registered, and there is considerable variation in the definition of such studies and the scope of registration in other EU countries. ${ }^{3}$ In this context, it should be of note that drug licensing and pharmacovigilance activities have been harmonised in the EU since $2001 .^{4}$

In the US, regulatory approval and registration of some post-marketing studies is required (such as interventional studies that must be registered under the US Food and Drug Administration Amendments Act of $2007^{5}$ ), but, unlike Germany, not all post-marketing studies have to be registered.

In light of the documented lack of knowledge about rare adverse drug reactions from pre-marketing randomised controlled trials ${ }^{6}$ and systematic under-reporting of spontaneous reporting schemes, ${ }^{7}$ German regulators, ${ }^{8}$ physician bodies, ${ }^{910}$ and statutory health insurers $^{11}$ have re-emphasised the importance and 
necessity of post-marketing studies for evaluating newly authorised drugs.

Despite Germany requiring the registration of all post-marketing studies, little is known on their size, cost, and nature. We therefore initiated freedom of information requests to obtain registration documents to understand the current state of post-marketing studies and evaluate whether these studies meet the aims specified in the Medicinal Products Act, particularly their potential to assess rare adverse drug reactions and thus help improve long term drug safety.

\section{Methods}

Registration of post-marketing studies in Germany takes place with three different authorities: the Statutory Health Insurance (Gesetzliche Krankenversicherung, GKV), the National Association of Statutory Health Insurance Physicians (Kassenärztliche Bundesvereinigung, KBV), and the drug regulator (Bundesinstitut für Arzneimittel und Medizinprodukte, BfArM).

Before a post-marketing study is started, the law requires a company to submit a notification to the three authorities, including time, location, duration, proposed number of patients and physicians, remunerations of physicians per patient, and drug/medical device under study. These notifications inform the agencies of a sponsor's intention to initiate a post-marketing study. In 2009, the Medicinal Products Act was revised to additionally require the inclusion of a study plan and final report a year after the study ended. The content of these notifications has not been publicly accessed or analysed before.

\section{Data sources}

In June 2011 we sent out identical freedom of information requests to the three authorities responsible for the registration of post-marketing studies in Germany, requesting the notifications received by these institutions from 1 January 2008 to 31 December 2010. We also requested access to documents to assess, for each reported study, the issuer of the notification, be it the drug manufacturer itself or a contract research organisation, and the proposed starting date and duration of the study.

In December 2011, GKV provided a tabulated listing of requested items on 48 pages, excluding physician remunerations; no access to original documents was granted. $\mathrm{KBV}$ and the drug regulator initially denied our requests with the rationale that answering our questions would mean too much work for their responsible officers and moreover interfere with the agreements on confidentiality and protection of business secrets included in the contracts signed by the involved parties. Transparency International Germany (of which some of us are members) therefore sued both KBV and the drug regulator and, in June 2012, prevailed in the lawsuit against KBV in the administration court of Berlin and, in July 2014, over the drug regulator in the administration court of Cologne. As a result of the lawsuit against KBV, we received 6925 paper copies of original documents, representing a mix of emails, letters, pre-study documents such as contracts, details of the studies, study plans, and lists of par- ticipating physicians. All documents were those received by the KBV; none were documents that originated from the KBV (that is, those sent by the KBV to the company that submitted the notification), though we requested such documents as well. This could be an indication that the KBV does not correspond with the companies regarding post-marketing studies. Personal data such as physicians' names and addresses and names of contract research organisations were redacted by KBV. At a later stage, however, KBV gave us the names of contract research organisations on a separate list, complying with our request. In April 2015, the drug regulator released to us 142 tabulated electronic pages of items related to post-marketing study notifications during 2008-10, but again denied access to original documents.

The German Medicinal Products Act requires that a company initiating a post-marketing study must file an identical notification of the study with three authorities-namely, KBV, GKV, and the drug regulator. Under the law, the three authorities should receive and therefore report the same number of notifications for the three year period 2008-10. The fact that the three authorities disclosed a range in number of post-marketing studies ( 499 from the drug regulator, 558 from KBV, and 598 from GKV) was unexpected. As only KBV was forced by the court ruling to provide us with original notification documents, we decided that the KBV data are the most reliable data source.

We used the AMIS website of DIMDI (Deutsches Institut für Medizinische Dokumentation und Information ${ }^{12}$ ) and the European Medicines Agency (EMA) database on medicines ${ }^{13}$ to determine each drug's year of marketing authorisation, and we searched the drug regulator's pharmacovigilance database of adverse drug reactions ${ }^{14}$ to determine if any of the publicly reported reactions could be linked with a registered post-marketing study by searching for the respective drug within the time frame of the study. We defined a "newly authorised drug" as a drug that was approved no longer than two years before the start of the study. This cut off was chosen to capture the early post-marketing phase of a drug, the period when previously unknown adverse drug reactions tend to show up with a high probability of detection. ${ }^{15}$ To assess the extent to which registered post-marketing studies are published, we searched Medline and PubMed from 2008 to 2015 with the following search strategy: "non-interventional PMS OR post-marketing NIS OR company observational PMS OR industry funded post-marketing trial OR adverse drug reaction AND (when available) the study ID AND drug name”.

Furthermore, we asked the drug commission of the German Medical Association (DCGMA) to search their adverse drug reaction database ${ }^{16}$ from 1 January 2009 to 31 December 2012 for solicited reports on the drug dabigatran etexilate and to link these reports to the respective post-marketing study identification numbers.

\section{Patient involvement}

No patients were involved in setting the research question or the outcome measures, nor were they involved in developing plans for recruitment, design, or implemen- 
tation of the study. No patients were asked to advise on interpretation or writing up of results. There are no plans to disseminate the results of the research to study participants or the relevant patient community.

\section{Analysis}

As original documents could be obtained only from the $\mathrm{KBV}$, we used these data for all analyses. We extracted data on the drugs/medicinal products under study, the intended number of patients, the intended number of physicians, the proposed remunerations, and purpose of study (study plan).

Experienced data managers from the Comprehensive Cancer Centre Aachen independently performed double entry of the complete dataset of original documents. The revised dataset was analysed with descriptive statistics, providing counts, percentages, ranges, means, and medians.

\section{Results}

The drug regulator, KBV, and GKV reported different numbers of post-marketing studies during the same time period, 2008-10. The drug regulator reported 499, KBV 558, and GKV 598. The following results are based on the 558 studies reported to the KBV. Table 1 summarises key characteristics of the post-marketing studies, stratified by year of registration.

During 2008-10, each year 185-188 post-marketing studies were initiated, sometimes more than one on the same drug. This is why the summary figure for the variable "unique drugs" adds up only to 330. Often a sponsor initiated several post-marketing studies.

Out of the 558 post-marketing studies, 445 were planned to take place only in Germany, 41 in Germany and the EU, and 25 multinationally, including the US and other countries outside the EU. Information on location was missing in 47. About a half were conducted by contract research organisations, which were responsible for data handling, reporting to the sponsor, and notifying the regulatory authorities about the conduct of the study.

Fifty four percent $(304 / 558)$ of the notifications were fewer than 10 pages long, with $11 \%$ (63/558) fewer than three pages. Notifications with 10 or more pages increased to $55 \%$ in 2010 . Table 2 shows the large range of length per notification. Over the full study period, $72 \%$ of notifications had no study plan or protocol. Though study plans have been required for notifications since 2009, only $21 \%$ in 2009 and $40 \%$ in 2010 had a study plan or protocol. Notifications also sometimes lacked other fields such as intended number of patients (17\% missing), intended number of physicians (15\%), and physicians' remuneration (35\%).

Table 2 also shows the requested and obtained information on the 558 notifications registered by the KBV. The median number of patients covered by a post-marketing study was 600 (mean 2331), with a broad range from two to 75000 . The median number of participating physicians was 63 (mean 270), ranging from 0 to 7000. We calculated a ratio of patients to physicians for each study, with a median of eight and a mean of 85 patients per physician, and a range of one to 10000 patients per physician. The reported median patient based remuneration was $€ 200$ (mean €441, range €0-€7280). Total remuneration costs per study were more than $€ 500000$ on average, and overall remuneration costs were more than $€ 217 \mathrm{~m}$ for 558 studies registered in a three year period. The calculated remuneration per physician per study amounted to a median of €2000 (mean €19424; range €0-€2080 000).

Table 3 shows a stratification of all notifications of post-marketing studies and of the subgroup of 171 studies of newly authorised drugs by category of intended

Table 1 | Characteristics of notifications of post-marketing studies by year, according to German National Association of Statutory Health Insurance Physicians (KBV)

\begin{tabular}{|c|c|c|c|c|}
\hline & 2008 & 2009 & 2010 & Total (2008-10) \\
\hline No of studies & 185 & 185 & 188 & 558 \\
\hline No of doctors & 41834 & 41961 & 42967 & 126762 \\
\hline Remuneration to physicians (€) & 63144276 & 60988903 & 93720505 & 217853684 \\
\hline No of unique drugs & 154 & 154 & 152 & 330 \\
\hline
\end{tabular}

Table 2 | Overview of information obtained on 558 notifications of post-marketing studies to German National Association of Statutory Health Insurance Physicians (KBV), 2008-10

\begin{tabular}{|c|c|c|c|c|}
\hline Requested information & $\begin{array}{l}\text { No }(\%) \text { with } \\
\text { information not } \\
\text { available }(n=558)\end{array}$ & Mean & Median (range) & Total \\
\hline No of pages per notification & $0(0)$ & 12 & $8(1-134)$ & 6925 \\
\hline Duration of study (days) & $14(2.5)$ & 738 & $480(24-7549)$ & 397064 \\
\hline Intended No of patients/study & $96(17.2)$ & 2331 & $600(2-75000)$ & 1077052 \\
\hline Intended No of physicians/study & $86(15.4)$ & 270 & $63(0-7000)$ & 126764 \\
\hline Physician remuneration/patient/study (€) & $76(13.6)$ & 441 & $200(0-7280)$ & NA \\
\hline Physician remuneration/study $(€)$ & $196(35.1)$ & 19424 & $2000(0-2080000)$ & 217853684 \\
\hline
\end{tabular}




\begin{tabular}{|c|c|c|}
\hline Intended No of patients & All studies $(n=558)$ & $\begin{array}{l}\text { Studies of newly } \\
\text { authorised drugs }(n=171)\end{array}$ \\
\hline $1-100$ & $65(11.6)$ & $9(5.3)$ \\
\hline $101-500$ & $162(29.0)$ & $53(31.0)$ \\
\hline $501-1000$ & $79(14.2)$ & $31(18.1)$ \\
\hline $1001-10000$ & $135(24.2)$ & $47(27.5)$ \\
\hline$>10000$ & $21(3.8)$ & $10(5.8)$ \\
\hline Not available & $96(17.2)$ & $21(12.3)$ \\
\hline
\end{tabular}

number of patients per study-that is, 1-100, 101-500, 501-1000, 1001-10 000, and $>10000$ patients. Of the 558 studies, 55\% (306) comprised fewer than 1000 patients per study, and only 4\% (21) intended to include more than 10000 . Again, studies of newly authorised drugs had rather small sample sizes, with 54\% (93/171) enrolling $<1000$ patients per study. Only about a third of the studies for newly authorised drugs were designed for more than 1000 patients, with just 15\% (26/171) including more than 3000 patients.

In contrast with the planned patient enrolment, the notification documents showed that the intended number of participating physicians per study was relatively high, with substantial variability across proposed study sample sizes. While more than half (306) of all studies intended to enrol fewer than 1000 patients, nearly half (147/306) of these studies included more than 20 physicians (table 4), leading to a low ratio of patients to physicians per study.

Although mandatory by law, information on numbers of participating patients and/or physicians was lacking in 33\% (182) of post-marketing studies (table 4).

Figure 1 shows the calculated physicians' remuneration per post-marketing study by different categories of patient enrolment. Across all enrolment categories the range of remuneration was wide, with no clear trend between study size and calculated remuneration. With up to 1000 enrolled patients, the most common category of physician remuneration was €1000-€10000, with about $10 \%$ of physicians earning up to $€ 50000$. In larger studies, $16 \%$ of physicians were paid more than $€ 10000$, some of them earning more than $€ 200000$ per study.

As shown in figure 2, the 558 post-marketing studies covered a broad range of pharmaceutical and non-drug products: biologicals, oncology drugs, antipsychotic drugs, antivirals, contrast agents, hormonal treatments, antihypertensives, haematology drugs, and orphan drugs as well as non-prescription drugs. A third of the studies covered recently authorised drugs (less than two years before the start of the post-marketing study); in these studies remuneration for physicians was on average twice as high compared with studies of other medicinal products (data not shown).

Among the 158 study plans submitted to the KBV we found contracts on the duties and obligations of physicians and sponsors, including confidentiality clauses.

Figure 3 shows an example of a confidentiality agreement, explaining that data, information, and results of a post-marketing study are strictly confidential and the sole property of the respective sponsor. Finally, we were not able to identify any reports on adverse drug reactions from the 558 post-marketing studies in the drug regulator's public adverse drug reactions database. For only five of all 558 post-marketing studies were we able to find a respective paper in a scientific journal.

\section{Discussion}

\section{Principal findings}

Our analysis of previously inaccessible original notification documents on post-marketing studies registered 2008-10 shows the extensive use of human and financial resources. In this three year period more than a million patients and over 126000 physicians (not necessarily unique) were estimated to have participated in 558 post-marketing studies, sponsored by 148 manufacturers of drugs or medicinal products. These companies spent more than $€ 217 \mathrm{~m}$ on physicians' remunerations alone.

The practice of post-marketing studies we describe takes place in many EU countries, such as Italy, France, Spain, and Austria. ${ }^{3}$ In contrast with these other countries, however, only in Germany do all such studies have to be registered. We therefore think there is good reason to believe that the German data we analysed are representative of post-marketing studies across the EU.

The quality of the documentation was low, and there were substantial deviations from legal requirements specified in the German Medicinal Products Act with respect to the aims and conduct of post-marketing studies. The large range in length of notification documents reflects the considerable heterogeneity of sponsors' approach to registration requirements. The median of eight pages raises questions about whether studies are being sufficiently described before they start.

Looking at the study plans, which were present in only 158 of 558 notifications, the designs mostly consisted of case series, ${ }^{17}$ often labelled with ambiguous terms such

Table 4 | Categories of intended participating physicians by intended patient enrolment in notifications of postmarketing studies. Figures are numbers (percentages), with percentages calculated by row

\begin{tabular}{|c|c|c|c|c|c|c|c|}
\hline \multirow{2}{*}{$\begin{array}{l}\text { Intended No of } \\
\text { patients }\end{array}$} & \multirow{2}{*}{$\begin{array}{l}\text { Total No } \\
\text { of studies }\end{array}$} & \multicolumn{6}{|c|}{ Intended No of participating physicians } \\
\hline & & $1-20$ & $21-100$ & $101-500$ & $>500$ & None & Not available \\
\hline $1-100$ & 65 & $45(69.4)$ & $5(7.6)$ & $1(1.5)$ & - & - & $14(21.5)$ \\
\hline $501-1000$ & 79 & $11(13.9)$ & $21(26.6)$ & $36(45.6)$ & $1(1.3)$ & - & $10(12.6)$ \\
\hline $1001-10000$ & 135 & $10(7.4)$ & $16(11.8)$ & $60(44.4)$ & $37(27.4)$ & - & $12(8.9)$ \\
\hline Total & 558 & 143 & 138 & 132 & 56 & 3 & 86 \\
\hline
\end{tabular}




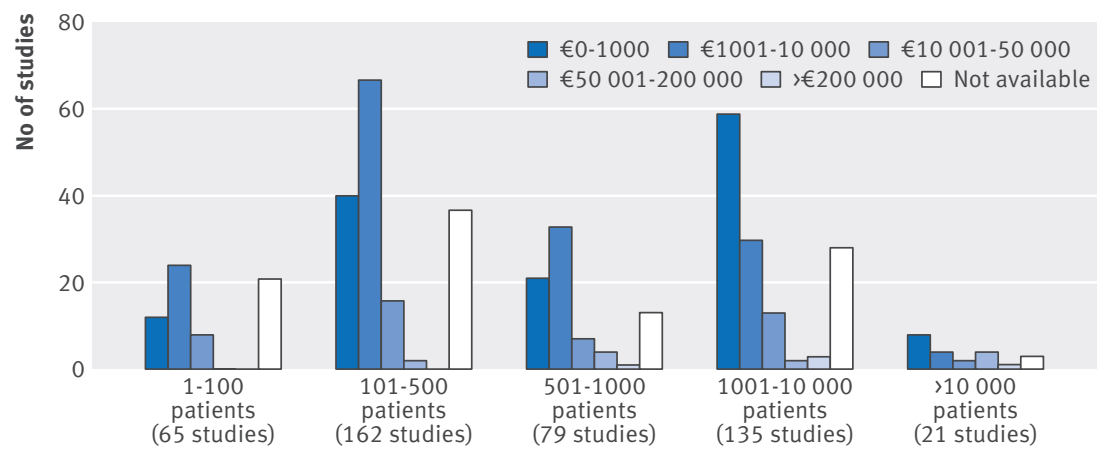

No of patients

Fig 1 Calculated physician remuneration per post-marketing study by different categories of patient enrolment. Total is 462 ; for 96 studies information on intended number of patients was not available

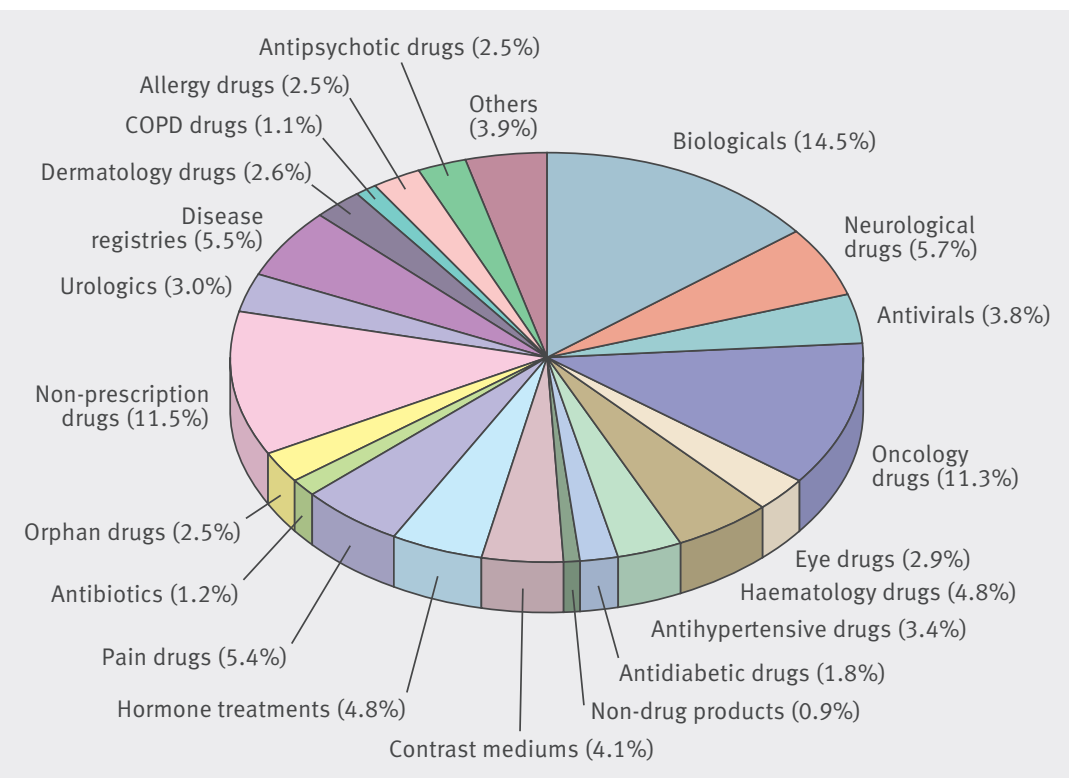

Fig 2 | Overview of classes of drugs and treatments (percentage) in post-marketing study notifications 2008-10 as single arm cohort studies or prospective studies. In the context of drug safety research, arbitrarily selected case series of patients receiving the study drug without a suitable comparison group are prone to bias and make interpretation of the results difficult, if not impossible. ${ }^{17}$

Compared with a descriptive study of premarket trials underpinning drug approval, ${ }^{18}$ we found that post-marketing studies had lower patient enrolment (median 760 enrolled in trials versus 600 planned in studies) but were of considerably longer duration (98 days for pre-market trials versus 480 days for post-marketing studies). For example, according to EMA information, ${ }^{19}$ lenalidomide (Revlimid) has been investigated with two randomised controlled trials involving a total of 2000 patients, one comparing lenalidomide with placebo, the other against a standard treatment for multiple myeloma. In the post-marketing study on lenalidomide only 100 patients and 18 physicians were involved. Dabigatran etexilate (Pradaxa) ${ }^{20}$ has been investigated with two main studies comparing the drug with enoxaparin, another anticoagulant, in patients who had undergone a hip or knee replacement. The first study involved 2101 patients who had had a knee replacement operation, and the second involved 3494 patients who had had a hip replacement. In our dataset we found two post-authorisation safety studies (PASS) on dabigatran (PASS 1160.84 and PASS 1160.85). These studies were mandated post-marketing studies because of specific safety concerns raised by regulatory agencies during drug approval. In PASS 1160.84, 300 patients with renal impairment were undergoing knee or hip replacement. PASS 1160.85 included 2036 patients with normal renal function undergoing hip or knee replacement. These few examples illustrate that the median number of patients enrolled in our sample of post-marketing studies (600 patients) tends to be smaller than the respective numbers (760 patients) recently described for pre-marketing randomised controlled trials. ${ }^{18}$ Less than a third of post-marketing studies, including those on newly authorised drugs, planned to include more than 1000 patients. Given that the probability of discovering one rare adverse drug reaction with an incidence of 1 in 10000 requires a large sample size of at least 30000 patients (achieving a power of 95\%), ${ }^{6}$ these enrolment figures seem far too small to meet the specified objectives of post-marketing studies to contribute to pharmacovigilance and drug safety. With respect to the regulators, it is unclear what authorities do with the notifications they receive, considering that many of the notifications we obtained were missing required fields. The GKV and the KBV entered the information into a post-marketing study database, which they use for internal purposes. Until 2015, however, the drug regulator did not systematically file the notifications but instead registered them as a regular postal document in consecutive order of daily mail arrivals.

Our attempts to identify reports on adverse drug reactions from the 2008-10 post-marketing studies in the adverse event database (Unerwünschte Arzneimittelwirkung (UAW) ${ }^{14}$ ) were unsuccessful. The drug regulators' UAW database contains spontaneous reports from 
individual physicians and solicited reports-that is, adverse drug reaction reports provided by manufacturers from pre-marketing or post-marketing studies or other sources-without linking of these solicited reports to post-marketing study notifications. To our knowledge the drug regulator, $\mathrm{KBV}$, and GKV did not receive individual patient documents from any study. Of the 558 post-marketing studies we were able to find only five journal articles that reported results of these studies in the databases we searched up to 2015. As only less than $10 \%$ (53) of studies were planned to finish after the end of 2013 we think there should have been enough time for most to be published. Even in the publicly accessible study registries of the Association of Researching Pharmaceutical Manufacturers (Verband der forschenden Arzneimittelhersteller), or the clinicaltrials.gov registry, final reports or references to publications of the 558 post-marketing studies were sparse with hardly any agreement between the different trial registries. Our findings suggest that it is not only regulators in the automotive sector who "have to ask tougher questions about how their rules are being implemented." 21

\section{Purpose of post-marketing studies}

Post-marketing studies have been criticised for their low scientific value. ${ }^{22}$ The main criticism relates to what Marcia Angell has called "marketing masquerading as research,"23 - that is, studies that are carried out for commercial reasons, not scientific ones, raising questions about their ethical basis. ${ }^{2425}$ In addition, the more expensive drugs used in so called "seeding trials"-sometimes called marketing trials-impose considerable extra costs to the healthcare system without measurable benefit to patients. ${ }^{26}$ The existence of seeding trials has been verified by confidential documents accessible to medical experts testifying in legal proceedings, ${ }^{27} 28$ but gauging their prevalence has been difficult. ${ }^{29}$ The low ratio of patients to physicians that other authors have observed in seeding trials ${ }^{2728}$ was also observed in our study and is conducive to low data quality as the training and monitoring of many physicians, each treating only a few patients, is cumbersome and inefficient. ${ }^{28}$

\section{Adverse event reporting}

Bearing in mind that spontaneous reporting is thought to cover $10 \%$ of all serious adverse drug reactions and less than $5 \%$ of non-serious ones, ${ }^{30}$ the current practice of post-marketing studies is likely to aggravate the under-reporting of adverse drug reactions. Our data show that participating in a post-marketing study is acceptable among a considerable proportion of physicians in Germany. In the contracts we reviewed we found confidentiality clauses requiring physicians to report adverse drug reactions exclusively to the sponsor rather than to the spontaneous reporting scheme. This raises the question of whether such contracts represent a conflict of interest with the physicians' professional code of conduct ${ }^{31}$ as it would necessarily diminish their individual, direct role in reporting of such events. Furthermore, we were unable to assess whether adverse drug reactions occurring within our sample of studies were also reported by the sponsor to the respective authorities. In the above mentioned study on dabigatran etexilate, for example, we found indications that adverse drug reactions occurring within post-marketing studies might have never or only partially been reported. Shortly after market authorisation of dabigatran, a new anticoagulant licensed in 2008 for prevention of thrombosis in patients after hip and knee replacement, the manufacturer initiated two post-authorisation safety studies, which were among the notifications to the KBV (PASS 1160.84 and PASS 1160.85). Severe side effects of dabigatran, especially bleeding complications and death, have been reported, especially in elderly patients with impaired renal function. ${ }^{32}$ In addition, previously undisclosed data from pre-marketing trials on dabigatran had shown that the risk of bleeding and the necessity of measuring plasma concentrations in patients taking dabigatran were downplayed by the manufacturer. ${ }^{33}$ In contrast with PASS 1160.85 , comprising 2036 patients with normal renal function, PASS 1160.84 intended to enrol 300 patients with moderate impairment of renal function. While we could find a link to the tabulated final synopsis on PASS 1160.85 published in 2013 in the clinicaltrials.gov database, ${ }^{34}$ PASS 1160.84 was not finished at the projected date (1 February 2012) nor was any final report or reference to results or side effects retrievable from Pharmacovigilance Risk Assessment Committee (PRAC) reports or other sources before 2015. Instead, by June 2014, more than two years after the scheduled end date, the drug regulator and KBV received a change notification of the termination date to 2014. Based on the documents that were provided it seemed that neither the drug regulator nor other authorities had taken notice of the course of PASS 1160.84. When we attempted to obtain specific information on adverse drug reactions on PASS 1160.84 between 2009 and 2012 from the solicited reports to the DCGMA database it turned out that the 68 severe adverse drug reactions could not be linked to any PASS/post-marketing study on dabigatran. ${ }^{35}$ It was not until June 2015 that a tabulated result section including adverse drug reactions of PASS 1160.84 was added to the respective clinicaltrials.gov study page. ${ }^{36}$ No reference to time of occurrence of serious adverse events was provided. Considering the legal obligation of reporting serious adverse events within 15 days after learning about the event, ${ }^{37}$ it is of concern that PASS 1160.84 was not terminated at the projected date but three years later, without any explanation why the study period was so much prolonged and with no traceable hints to PASS 1160.84 in PRAC reports during 2009-15. It is worth noting that after the initiation of a post-authorisation safety study, oversight by PRAC with periodic reporting is required.$^{4}$ Our findings, however, highlight the fact that if reporting of adverse drug reactions from a post-authorisation safety study/post-marketing study is delayed or occurs in such a way that does not allow a determination of whether events listed in a pharmacovigilance database occurred under a post-marketing study or not, this is concerning from a transparency and public health perspective. Our research points out that not only in sponsor directed randomised controlled trials ${ }^{38}$ but also in post-marketing studies, withholding of data on adverse 
drug reactions or other information by the sponsor is a problem that so far has not been adequately dealt with.

Data from the UK and the US have shown that by the mid-1990s, 5\% of hospital admissions and $0.1 \%$ of deaths of medical patients and $0.01 \%$ of deaths of surgical patients were caused by adverse drug reactions. ${ }^{6}$ Some 20 years later drug prescribing habits of doctors have skyrocketed, ${ }^{39}$ with prescription patterns following industry payments. ${ }^{40-42}$ Some authors have documented that the number of reports of adverse drug reactions decreased by $58 \%$ in some areas of the UK during the past two decades. ${ }^{43}$ This study found a strong correlation between high prescription rates and low spontaneous reporting of adverse drug reactions by GPs in the UK. ${ }^{43}$ Assuming that industry payment for participation in post-marketing studies is one reason for increased prescribing of drugs, as suggested by the literature on seeding trials, 252728 the decreases in reporting of adverse drug reactions over time should be of concern as a possible unintended consequence of post-marketing studies. We cannot exclude that signing of post-marketing study confidentiality contracts in combination with the high remunerations could influence physicians' attitudes and practice of reporting adverse drug reactions, in particular when contracts require physicians to report reactions exclusively to the sponsor, as we found was the case in our study. From the patients' and public health perspective, such influences on physicians are detrimental as they undermine the prominent and irreplaceable role of GPs/clinicians in detecting, diagnosing, and reporting adverse drug reactions for continued drug safety monitoring. ${ }^{6}$

\section{Strengths and limitations of study}

For the first time we have analysed previously inaccessible original notification documents provided by 148 manufacturers of drugs or medicinal products over a three year period on their post-marketing study activities. In particular, we found contracts with strict confidentiality clauses that had not been available for public scrutiny before. These were obtained after two lawsuits and administrative court rulings granting freedom of information rights on notification data from post-marketing studies.

Our study has limitations. As mentioned before we analysed original notification documents but not real study data. The notification documents provide data on planned studies, but we do not know how these post-marketing studies were carried out in reality. For example, we do not know if the intended numbers of patients or physicians were really achieved in the course of the study. Our calculated number of 126000 participating physicians is likely to be an overestimate because physicians can participate in several post-marketing studies. Nor do we know anything about data quality and checks of data quality in these studies. We cannot be sure either, whether the physicians received more or less remuneration than envisaged. Our finding that most post-marketing studies were not published by 2015 in the databases we searched cannot exclude publications elsewhere. In light of the scientific purpose of post-marketing studies, however, published results of these studies should be traceable in established medical literature databases. Similarly our inability to connect the notifications with adverse drug reaction reports in the UAW database is because there is no tagging of the respective reaction reports with specific post-marketing studies. Therefore we cannot know whether the adverse drug reactions database contains reports from our sample of post-marketing studies.

Being aware that we looked only at original notifications rather than the real study documents and that the completeness of the given information was far from satisfactory, our results should be seen as a first estimate of the magnitude and potential risks incurred with current post-marketing study activities.

\section{Conclusions and policy implications}

Our findings do not support the aspiration of the German Medicinal Products Act that post-marketing studies serve to improve long term drug safety surveillance. In contrast, we found evidence that drug safety could be jeopardised by the current practice, as post-marketing studies are expected to contribute to pharmacovigilance, but in reality their data and results are treated as business secrets. Our data support the view that the high remunerations paid by the sponsor to the participating physician could be serving commercial purposes rather than transparent and effective pharmacovigilance. In our opinion the major problem with post-marketing studies is the confidentiality clauses in the contracts between physicians and sponsors. These contracts impose a major obstacle to scientific evaluation and discussion of post-marketing studies. In the interest of drug safety and public health, post-marketing surveillance should become more transparent. Data about and from such studies should no longer be considered confidential business information but should be made available to independent scientific evaluation and public scrutiny. Such increased transparency would allow future researchers to evaluate whether the changes in 2012 to EU pharmacovigilance legislation ${ }^{44}$ have been associated with any material improvements in the situation.

The importance of advising GPs and clinicians on their indispensable role in detecting, diagnosing, and reporting adverse drug reactions cannot be overestimated.

We thank Anke Martiny ${ }^{\ddagger}$ and Peter Schönhöfer from Transparency International (TI) Germany, for the idea of sending freedom of information requests on post-marketing studies to the authorities; Wolfgang Wodarg and Gerhard Guldner from TI Germany for their help with a first inspection of the notification documents; and the members of the working group on health of TI Germany for their valuable discussions and comments. We are also indebted to the board of TI Germany for ongoing support of the post-marketing studies project. Special thanks go to Christoph Partsch for valuable legal advice.

Contributors: AS conceived the study idea. AS and UK designed the study, performed the analyses, and drafted the manuscript. CP contributed to the drafting of the manuscript and helped to describe the role of post-marketing studies in other European healthcare systems. PD provided critical revisions to the manuscript. KO and TW helped with data management, control of data quality, and data analyses. DH helped with freedom of information requests and subsequent court trials and with data acquisition. All authors contributed to discussing and commenting on the paper. AS is guarantor.

Funding: The Board of Transparency International Germany provided financial resources for legal advice and fees related to assertion of freedom 
of information rights. The board had no influence on study design; in the collection, analysis and interpretation of the data; in the writing of the report; and in the decision to submit the paper for publication.

Competing interests: All authors have completed the ICMJE uniform disclosure form at www.icmje.org/coi_disclosure.pdf and declare: no support from any organisation for the submitted work other than Transparency International Germany; no financial relationships with any organisations that might have an interest in the submitted work in the previous three years; no other relationships or activities that could appear to have influenced the submitted work. PD is an unpaid member of the IMEDS steering committee at the Reagan-Udall Foundation for the FDA, which focuses on drug safety research. PD is also an associate editor at The BMJ.

Ethical approval: Not required.

Data sharing: Our dataset of post-marketing study notifications and extraction sheets will be made publicly available. The location will be announced in an online letter (rapid response) to this article.

Transparency: The lead author affirms that this manuscript is an honest, accurate, and transparent account of the study being reported, that no important aspects of the study have been omitted, and that any discrepancies from the study as planned have been explained.

This is an Open Access article distributed in accordance with the Creative Commons Attribution Non Commercial (CC BY-NC 4.0) license, which permits others to distribute, remix, adapt, build upon this work non-commercially, and license their derivative works on different terms, provided the original work is properly cited and the use is noncommercial. See: http://creativecommons.org/licenses/by-nc/4.0/.

1 Council for International Organizations of Medical Sciences (CIOMS). Reporting Adverse Drug Reactions. Definitions of Terms and Criteria for their Use, CIOMS 1999. http://www.cioms.ch/ publications/reporting adverse drug.pdf.

2 German Medicinal Products Act (AMG), section 4, subsection 23 , version 2004. Bundesgesetzesblatt 2004;1:2031.

3 McCully S. Conducting non-interventional studies in Europe. Attempts at Clarity lead to increased complexity. http://www. inventivhealthclinical.com/Collateral/Documents/English-US/ landing/Non-Interventional\%20Research_an_Feb\%202015.pdf.

4 European Regulation (EC) No 726/2004. Official Journal of the European Union L 2004;136:30.4

5 Food and Drug Administration Amendments Act. 2007. Section 801https://clinicaltrials gov/CT2/manage-recs/fdaaa.

6 Pirmohamed M, Breckenridge AM, Kitteringham NR, Park BK. Adverse drug reactions. BMJ 1998;316:1295-8. doi:10.1136/bmj.316.7140.1295. Lopez-Gonzalez E, Herdeiro MT, Figueiras A. Determinants of under-reporting of adverse drug reactions: a systematic review. Drug Saf 2009;32:19-31. doi:10.2165/00002018-200932010-00002.

8 von Jeinsen BKJG, Sudhop T. A 1-year cross-sectional analysis of non-interventional post-marketing study protocols submitted to the German Federal Institute for Drugs and Medicinal Devices (BfArM). Eur J Clin Pharmacol 2013;69:1453-66. doi:10.1007/s00228-013-1482-z.

9 Müller CH. Anwendungsbeobachtungen. Notwendig: Mehr Transparenz und Wissenschaftlichkeit. (Post-marketing noninterventional studies. More transparency and scientific value required.) [in German] Dtsch Arzteb/ 2009;106:A2042-44.

10 Wink K. Anwendungsbeobachtungen in der ärztlichen Praxis. Im Auftrag der Arzneimittelkommission der Deutschen Ärzteschaft. 2. Auflage Berlin 2010. (Post-marketing non-interventional studies in clinical practice. On behalf of the Drug Committee of the German Medical Association, in German) http://www.akdae.de/ Stellungnahmen/Weitere/20101218.pdf.

11 Dietrich ES, Zierold F. Evaluation der wissenschaftlichen Qualität von Anwendungsbeobachtungen (Evaluation of the scientific quality of post-marketing non-interventional studies, in German). https://www. tk.de/centaurus/servlet/contentblob/148560/Datei/1045/ Anwendungsbeobachtungen-Zusammenfassung.pdf.

12 AMIS. Central information system on medicinal products in co-operation with the German Drug Regulatory Authorities. http:// www.dimdi.de/static/de/amg/amis/

13 EMA Database of Medicines. http://wwwema europa eu

14 BfArM Datenbank Unerwünschte Arzneimittelwirkungen http://www. bfarm.de/DE/Arzneimittel/Pharmakovigilanz/RisikenMelden/ uawDB/ node.html

15 Hochberg AM, Hauben M, Pearson RK, O’Hara DJ, Reisinger SJ. Systematic investigation of time windows for adverse event data mining for recently approved drugs. J Clin Pharmacol 2009;49:62633. doi:10.1177/0091270009333484

16 Drug Commission of the German Medical Association. Arzneimittelkommission der deutschen Ärzteschaft Wissenschaftlicher Fachausschuss der Bundesärztekammer - UAW-Meldungenhttp://www.akdae.de/Arzneimittelsicherheit/ UAW-Meldung/Info/UAW-Meldung-Analyse.html

17 Porta M. Case series. In: A dictionary of epidemiology.5th ed. Oxford University Press, 2008: 33.
18 Downing NS, Aminawung JA, Shah ND, Krumholz HM, Ross JS. Clinical trial evidence supporting FDA approval of novel therapeutic agents, 2005-2012. JAMA 2014:311:368-77. doi:10.1001/jama.2013.282034.

19 Revlimid. http://www.ema.europa.eu/ema/index.jsp?curl=pages/ medicines/human/medicines/000717/human_med_001034. jsp\&mid=WC0b01ac058001d124

20 Pradaxa. http://www.ema.europa.eu/ema/index.jsp?curl=pages/ medicines/human/medicines/000829/human_med_000981. jsp\&mid=WC0b01ac058001d124

21 Testing times. Nature 2015:526:5.

22 Hasford J, Lamprecht T. Company observational post-marketing studies: drug risk assessment and drug research in special populations--a study-based analysis. Eur / Clin Pharmacol 1998;53:369-71. doi:10.1007/s002280050395.

23 Angell M. Marketing masquerading as research. In: The truth about the drug companies: how they deceive us and what to do about it Random House, 2004: 156-72.

24 London AJ, Kimmelman J, Carlisle B. Research ethics. Rethinking research ethics: the case of post-marketing trials. Science 2012:336:544-5. doi:10.1126/science.1216086.

25 Psaty BM, Rennie D. Clinical trial investigators and their prescribing patterns: another dimension to the relationship between physician investigators and the pharmaceutical industry. JAMA 2006;295:278790. doi:10.1001/jama.295.23.2787.

26 Kessler DA, Rose JL, Temple RJ, Schapiro R, Griffin JP. Therapeutic-class wars--drug promotion in a competitive marketplace. N Engl J Med 1994:331:1350-3 doi:10.1056/NEIM199411173312007.

27 Hill KP, Ross JS, Egilman DS, Krumholz HM. The ADVANTAGE seeding trial: a review of internal documents. Ann Intern Med 2008;149:251-8. doi:10.7326/0003-4819-149-4-200808190-00006.

28 Krumholz SD, Egilman DS, Ross JS. STEPS: A narrative account of a gabapentin seeding trial. Arch Intern Med 2011;171:1100-7. doi:10.1001/ archinternmed.2011.241.

29 Barbour V, Burch D, Godlee F, et al. Characterisation of trials where marketing purposes have been influential in study design: a descriptive study. Trials 2016;17:31. doi:10.1186/s13063-015-1107-1.

30 Rawlins MD. Pharmacovigilance: paradise lost, regained or postponed? The William Withering Lecture 1994. J R Coll Physicians Lond 1995;29:41-9.

31 Musterberufsordnung für die in Deutschland tätigen Ärztinnen und Ärzte -MBO-Ä 1997 - In der Fassung des Beschlusses des 118. Deutschen Ärztetages in Frankfurt am Main. http://www. bundesaerztekammer.de/fileadmin/user_upload/downloads/ pdf-Ordner/MBO/MBO_02.07.2015.pdf

32 Charlton B, Redberg R. The trouble with dabigatran. BMJ 2014;349:g4681. doi:10.1136/bmj.g4681

33 Cohen D. Dabigatran: how the drug company witheld important analyses. BMJ 2014;349:g4670. doi:10.1136/bmj.g4670.

34 Pradaxa (Dabigatran Etexilate $220 \mathrm{mg} /$ q.d. in the General Population After Hip or Knee Replacement Surgery. https://clinicaltrials.gov/ct2/ show/NCT00846807?term=Pradaxa+AND+dabigatran+etexilate\&id= 1160.85\&rank=1

35 Paulides M. Drug Commission of the German Medical Association (DCGMA). 2015

36 Pradaxa (Dabigatran Etexilate) $150 \mathrm{mg} /$ q.d. in Patients With Moderate Renal Impairment After Hip or Knee Replacement Surgery. https://clinicaltrials.gov/ct2/show/results/NCT00847301?recr= Closed\&cond=\%22Thrombosis\%22\&lead=boehringer\&rank= 19\&sect $=$ X012356\#all

37 German Medicinal Products Act (AMG). § 63b, Abs. 1-8, version 2004 Bundesgesetzesblatt 2004; Teill:2031-53

38 Doshi P, Jefferson T, Del Mar C. The imperative to share clinical study reports: recommendations from the Tamiflu experience. PLoS Med 2012;9:e1001201. doi:10.1371/journal.pmed.1001201.

39 Zhang F, Mamtani R, Scott Fl, Goldberg DS, Haynes K, Lewis JD. Increasing use of prescription drugs in the United Kingdom. Pharmacoepidemiol Drug Saf 2016;25:628-36. doi:10.1002/pds.3947.

40 Fleischman W, Agrawal S, King M, et al. Association between payments from manufacturers of pharmaceuticals to physicians and regional prescribing: cross sectional ecological study. $B M$ 2016;354:i4189. doi:10.1136/bmj.i4189.

41 Yeh JS, Franklin JM, Avorn J, Landon J, Kesselheim AS. Association of industry payments to physicians with the prescribing of brand-name statins in Massachusetts. JAMA Intern Med 2016;176:763-8. doi:10.1001/jamainternmed.2016.1709.

42 Delong C, Aguilar T, Tseng CW, Lin GA, Boscardin WJ, Dudley RA. Pharmaceutical industry-sponsored meals and physician prescribing patterns for Medicare beneficiaries. JAMA Intern Med 2016;176:111410. doi:10.1001/jamainternmed.2016.2765.

43 Cox AR, Anton C, McDowell SE, Marriott JF, Ferner RE. Correlates of spontaneous reporting of adverse drug reactions within primary care: the paradox of low prescribers who are high reporters. Br J Clin Pharmacol 2010;69:529-34. doi:10.1111/j.1365-2125.2010.03637.x.

44 Commission implementing regulation (EU) no 520/2012 of 19 June 2012. Official Journal of the European Union L 159/5-159/25 20.6.2012. http://eur-lex.europa.eu/LexUriServ/LexUriServ. do?uri=0|:L:2012:159:0005:0025:EN:PDF 